\title{
Verwendete Abkürzungen.
}

$A L=$ Arcliv der Familie von Lassaulx in Friedrichsfeld bei Wesel. StA $=$ Staatsarchiv in Koblenz. Die erste Ziffer gibt die Abteilung, die zxeite die Faszikelnummer an. Sind in einem Faszikel die Blätter oder Stücke gezählt, so wird die Blattziffer bzw. Stücknummer in Klammern beigefügt. Vgl. Charles Schmidt, Les sources de l'histoire des territoires rhénanes 1792-1814, Paris 1921. - Der Abteilung 256 ist in Klammern die Bezeichnung $\mathrm{PA}=$ Präfekturakten beigefügt.

$\mathrm{SC}=$ Stadtbibliothek Coblenz.

$\mathrm{UJ}=$ Universitätsbibliothek Jena.

$\mathrm{VS}=$ Varnhagensammlung der Staatsbibliothek in Berlin.

$\mathrm{AM}=$ Archiv der Stadt Mainz.

$\mathrm{A}=$ Anmerkung im gleichen Kapitel; bei Verweisen auf andere Kapitel ist die römische Nummer beigefügt.

$\mathrm{ADB}=$ Allgemeine deutsche Biographie.

$A L Z=$ Allgemeine I iteratur-Zeitung in Jena 1785-1803; von 1804 an sind die Jenaische und die Hallische L.-Z. durch Zusatz des Ortes in Klammern unterschicden.

$\mathrm{PRhG}=$ Publikationen der Gesellschaft für rheinische Geschichtskunde. Außerdem die allgemeinen literarhistorischen Siglen wic GGr, WA usw. 
